\title{
Experimental investigations to predict mean diameter of AA6082 tube in flow forming process - A DOE approach
}

\author{
M. Srinivasulu ${ }^{1}$, M. Komaraiah ${ }^{2}$, C.S. Krishna Prasada Rao ${ }^{3}$ \\ ${ }^{I}$ (Faculty in Mechanical Engg., Department of Technical Education,A.P., India-500 074) \\ ${ }^{2}$ (Srinidhi Institute of Science and Technology, Hyderabad, A.P., India-500014) \\ ${ }^{3}$ (Senior Addl. General Manager, Bharat Dynamics limited, Hyderabad A.P., India-500065)
}

\begin{abstract}
Flow-forming is effective, chipless metal forming process used for the manufacture of thin walled seamless tubes. In the present paper, a regression model has been developed to predict mean diameter of AA6082 flow formed tubes by Design Of Experiments. The process parameters chosen for the present investigation are axial feed of the roller, speed of the mandrel, and roller radius. Experiments are performed on a single roller flow forming machine to study the effect of process parameters on mean diameter of flow formed tube employing response surface methodology (RSM). The regression model generated by response surface methodology successfully predicts the mean diameter of AA6082 flow formed tube within the range of selected process parameters. It is found that, roller feed and roller radius are significant parameters influencing the mean diameter of Flow-forming AA6082 flow formed tube.
\end{abstract}

KEY WORDS- AA6082 alloy, Design Of Experiments, Mean diameter, Response surface methodology.

\section{INTRODUCTION}

Flow-forming is innovative, advanced manufacturing process for the production of thin walled seamless tubes. In flow-forming process, the length of pre-form is elongated by reducing wall thickness. The internal diameter of the pre-form remains unchanged. Flow-forming process is used for the manufacture of seamless tubes, cylinders, axi-symmetric sheet metal parts for high strength-to-weight ratio flanged components used in ship building, agricultural, railway, automobile, aerospace and missile applications etc. Outside mean diameter is one of the important parameter in the production of thin walled seamless tubes. Various process parameters namely roller feed, mandrel speed, roller radius, thickness reduction, roller attack angle influence the mean diameter of flow formed tube.

Kalpkcioglu investigated on the shear-spinnability of metals. Ram Mohan and Mishra made studies on the power spinning of tubes. Rajanish Prakash and Singhal conducted experiments on shear spinning of Titanium, Inconel 600 and AISI-304 steel and proved that the process can be used for the production of thinwalled, high precision long tubes on commercial basis. Park Jae-Woo et al. optimized the total power consumption by flexible tolerance method to minimize multi-variable non-linear function in tube-spinning processes by employing upper-bound stream-function method. Lee and $\mathrm{Lu}$ conducted experiments on flow forming of cylindrical tubes and concluded that, size of roller influence the deformation ratio and forming force. They also found that, better surface finish was produced with a larger roller. Wong et al. investigated the Effects of roller path and geometry on the flow forming of solid cylindrical components. They reported that, metal flow takes place predominantly in radial direction with cylindrical roller and predominantly in axial direction with nosed roller. Makoto Murata et al. studied the effect of setting temperature of roller tool on the forming properties of spinning. They found that, spinning force and hardness increases with the increase of setting reduction. Joseph Davidson et al. studied effect of process parameters on the quality of AA6061 flow formed tubes. They proposed the optimum parameters for good surface characteristics. Razani et al. studied the out of roundness of AISI 321 steel tube by flow forming process employing Taguchi method. But, very small work has been found on flow forming of AA6082 tubes. The mean diameter is one of the important characteristic and precise control of average diameter of AA 6082 tube in flow forming is essential for critical aerospace and missile applications.

Alauddin et al. Predicted tool life in end milling process employing response surface methodology. Gunaraj and Murugan used response surface methodology to predict weld bead quality in submerged arc welding of pipes. Jae-Seob Kwak studied the effect of process parametrs on the geometric error in grinding process and developed regression model to predict geometric error using Taguchi and response surface methodologies. Joseph Davidson et al. predicted surface roughness of AA6061 flow formed tubes by response surface methodology. Srinivasulu et al. used Taguchi method for optimizing the process parameters to produce the tubes with minimum surface roughness in flow forming of AA 6082 annealed pre-forms. 
The literature review reveals that, no work has been reported on regression modeling for the manufacture of AA6082 thin walled tubes with precise mean diameter by flow forming process.

The aim of present investigation is to generate the regression model to predict the mean diameter of AA6082 thin walled tubes manufactured by flow forming process. The input process parameters selected for the present study are axial feed of the roller, speed of the mandrel and roller radius. The response parameter is the mean diameter of flow formed tube.

\subsection{Material}

\section{EXPERIMENTAL WORK}

The material selected for the present research is AA6082 alloy. The composition of AA6082 alloy is given in table-1. It has medium strength, good machinability and wedability with excellent corrosion resistance. Addition of Manganese controls the grain structure, which results in superior strength. The alloy age hardens by formation of $\mathrm{Mg}_{2} \mathrm{Si}$ precipitates. This alloy has an ultimate tensile strength of $340 \mathrm{MPa}$, yield strength of 310 $\mathrm{MPa}$ and hardness of $95 \mathrm{BHN}$. AA6082 alloy used in automobiles, truck frames, ship building, motor boats, pylons, towers, aero space and missile applications.

TABLE-1

Composition of AA6082 alloy

\begin{tabular}{|c|c|c|c|c|c|c|c|}
\hline Element & $\mathrm{Al}$ & $\mathrm{Mg}$ & $\mathrm{Mn}$ & $\mathrm{Si}$ & $\mathrm{Fe}$ & $\mathrm{Cr}$ & $\mathrm{Cu}$ \\
\hline $\boldsymbol{\%}$ & 95.65 & 1.20 & 1.00 & 1.3 & 0.50 & 0.25 & 0.10 \\
\hline
\end{tabular}

\subsection{Flow forming process}

In flow forming, a short and thick cylindrical blank (Pre-form), is stretched on a rotating mandrel by means of mechanically guided rollers. The pre-form is lengthened by decreasing in wall thickness. It is locked by means of serrations and rotates together with the mandrel at the same speed. The forming roller follows the contour of the mandrel with a preset gap. The gap between the rotating mandrel and the roller acts as an orifice through which the metal flow occurs (extruded). As the forming process produces localized deformation, lower forces are required as compared to other processes. The principle of flow forming is shown in Figure 1.

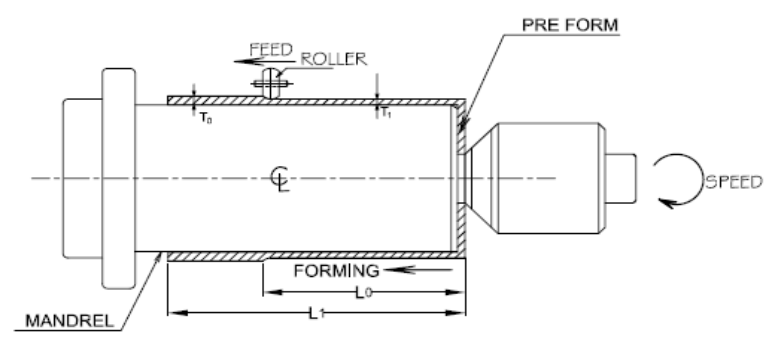

Fig. 1. Flow forming process

The flow forming is classified into two types as forward flow forming and backward (reverse) flow forming processes. In forward flow forming, the material flow takes place in the same direction as that of rollers. The forming is done near tail stock and requires tubes with closed ends. Material flows in the opposite direction to the roller feed in case of backward flow forming. Tubes longer than mandrel can be formed in backward flow forming process.

\subsection{Pre-form Design}

The design of pre-form was based on two parameters namely maximum possible deformation and constant volume principle. These pre-forms were made by hot forging. Generally $15 \%$ allowance is provided on the diameter for machining and other allowances. The pre-form was subjected to annealing at a temperature of $550^{\circ} \mathrm{C}$ for two hours to take the precipitation into solution and quenched in water to retain solute in solution. The mandrel is made up of tool steel and hardened to 63HRC. A thin film of lubricant is applied on mandrel to avoid sticking of flow formed tube. The machined pre-form is shown in fig. 2.

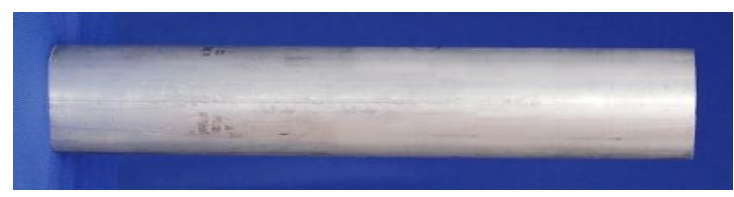

Fig. 2. Machined Pre-form 


\subsection{Equipment}

The present research work is carried out on a CNC flow-forming machine with single roller. The mandrel rotates at a speed, $\mathrm{S} \mathrm{rpm}$. The roller moves along the axis of the mandrel with a feed rate, $\mathrm{F} \mathrm{mm} / \mathrm{min}$ and decreases the thickness of pre-form when a thickness reduction $\mathrm{t}(\%)$ is given by radial feed. The thickness reduction is effected by maintaining gap between the mandrel and the roller less than the thickness of pre-form. The axial and radial feeds are maintained by hydraulic power pack through servo motors. The thickness reduction of pre-form results in increase in length without altering inside diameter. It is aimed to manufacture seamless tubes with maximum percentage elongation ratio, good strength and minimum mean diameter.

\subsection{Design Of Experiments (DOE)}

\section{THE METHODOLOGY}

In the present research, Design Of Experiments, a powerful statistical tool is employed to achieve predictive knowledge of complex, multivariable process with minimum experimentation. It reduces the cost of experimentation and gives meaningful, valid conclusion with least number of experiments. This technique helps to identify the significant input process parameters. DOE also enables to determine the individual and interaction effects of input process parameters that could influence the response function. Response surface methodology (RSM) a statistical and mathematical method based on Design Of Experiments is employed to model mean diameter in flow forming of AA 6082 tubes.

\subsection{Response surface methodology (RSM)}

Response surface methodology is a collection of statistical and mathematical methods that are useful for the modeling and analyzing engineering problems. The main objective of this technique is to optimize the response function that is influenced by different process parameters. Response surface methodology also quantifies the relationship between the controllable input parameters and obtained response surface. The design procedure of RSM is as follows:

1. Identification of controllable input process parameter and desirable response parameter.

2. Planning of a series of experimental runs as dictated by design matrix for adequate and reliable measurement of the response function.

3. Developing a mathematical model of the second order response surface with the best fittings.

4. Finding the optimal combination of experimental parameters that gives a maximum or minimum value of response.

5. Reporting the direct and interactive effects of process parameters on the response through two and three dimensional plots.

\subsection{Box-Behnken design}

Box-Behnken design is one of the popular response surface designs is used in the present investigation. Box-Behnken design requires only three levels for each parameter. It has no points at the vertices of the cube defined by the ranges of the factors. This distinguished feature is sometimes useful when it is desirable to avoid the points at corner of the cube due to engineering considerations. For two or three factors, it requires fewer experimental runs as compared to compared to the central composite design. The design matrix requires 17 experimental runs only to model the process

\section{SELECTION OF INPUT PROCESS PARAMETRES}

Initially trial runs were conducted to know the effect of various process parameters on the mean diameter in flow forming of AA 6082 tubes. The input process parameters chosen based on trial experiments. The input process parameters selected for the present investigation are axial feed of the roller, speed of the mandrel and radius of the roller. The input process parameters and their low and high levels are given in Table 2. The response surface model for mean diameter of flow formed tube is developed by trial version of Design Expert 8.0 software.

TABLE-2

Input Process parameters and their levels

\begin{tabular}{|c|c|c|c|}
\hline Sl. No. & Parameters & Low level & High level \\
\hline 1 & Axial feed, $\mathrm{mm} / \mathrm{min}$. & 50 & 100 \\
\hline 2 & Mandrel speed, $\mathrm{rpm}$ & 150 & 250 \\
\hline 3 & Roller radius, $\mathrm{mm}$ & 4 & 12 \\
\hline
\end{tabular}




\section{DEVELOPING MATHEMATICAL MODEL FOR MEAN DIAMETER}

The experimental plan is generated by Design Expert Version 8.0 software is given in Table 2. The experimental runs were conducted with different combinations of input process parameters as dictated by BoxBehnken design martix. The mean diameter of flow formed tube for each experimental run is measured by a bore dial gauge. The resolution of bore dial gauge is $0.01 \mathrm{~mm}$. The mean diameter is calculated by the average of diameters at selected points on the flow formed tube. The measurement is taken at five points with a gap of 10 $\mathrm{mm}$ and is repeated for every $50 \mathrm{~mm}$ length of the tube.

The response parameter values are given in Table 3. In the present investigation, equation for response function in terms of selected input process parameters obtained by using trial version of Design Expert 8.0 software. The flow formed tubes are shown in figure 3.

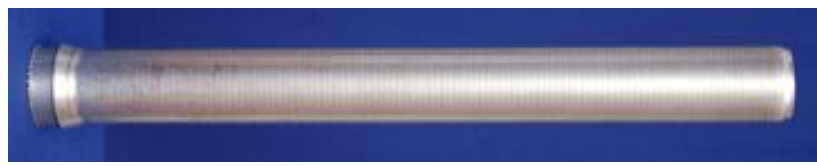

Fig. 2 Flow formed tube

The response equation generated by the model for mean diameter is given by

$$
\begin{aligned}
\text { Mean diameter }(\mathrm{D})= & +56.33-0.25315 \times(\text { Feed })-0.024075 \times(\text { Speed })-0.295 \times(\text { Radius }) \\
& -1.620 \mathrm{E}-04 \times(\text { Feed } \times \text { Speed })+3.15 \mathrm{E}-03 \times(\text { Feed } \times \text { Radius }) \\
& +8.0 \mathrm{E}-04 \times(\text { Speed } \times \text { Radius })+1.77 \mathrm{E}-03 \times(\text { Feed })^{2}+7.45 \mathrm{E}-05 \times(\text { Speed })^{2} \\
& -4.45313 \mathrm{E}-03 \times(\text { Radius })^{2}-----(1)
\end{aligned}
$$

Table-3

Experimental layout using Box-Behnken design

\begin{tabular}{|c|c|c|c|c|}
\hline \multirow{2}{*}{ Run No. } & \multicolumn{3}{|c|}{ Parameters } & $\begin{array}{c}\text { Mean diameter } \\
\text { (In side }) \\
\text { D }(\text { mm })\end{array}$ \\
\hline 1 & $\begin{array}{c}\text { Feed } \\
(F)\end{array}$ & $\begin{array}{c}\text { Speed } \\
(S)\end{array}$ & $\begin{array}{c}\text { Radius } \\
(R)\end{array}$ & 43.56 \\
\hline 2 & 75.00 & 200.00 & 8.00 & 43.56 \\
\hline 3 & 75.00 & 200.00 & 8.00 & 43.73 \\
\hline 4 & 100.00 & 200.00 & 12.00 & 45.10 \\
\hline 5 & 50.00 & 200.00 & 12.00 & 44.25 \\
\hline 6 & 75.00 & 200.00 & 8.00 & 43.56 \\
\hline 7 & 100.00 & 250.00 & 8.00 & 44.85 \\
\hline 8 & 75.00 & 200.00 & 8.00 & 43.56 \\
\hline 9 & 75.00 & 200.00 & 8.00 & 43.56 \\
\hline 10 & 100.00 & 200.00 & 4.00 & 44.31 \\
\hline 11 & 50.00 & 250.00 & 8.00 & 44.96 \\
\hline 12 & 50.00 & 150.00 & 8.00 & 44.45 \\
\hline 13 & 100.00 & 150.00 & 8.00 & 45.15 \\
\hline 14 & 75.00 & 150.00 & 4.00 & 43.73 \\
\hline 15 & 75.00 & 250.00 & 12.00 & 43.94 \\
\hline 16 & 75.00 & 250.00 & 4.00 & 43.30 \\
\hline 17 & 50.00 & 200.00 & 4.00 & 44.72 \\
\hline
\end{tabular}

\section{RESULTS AND DISCUSSION}

\subsection{ANOVA}

The influence of input process parameters on the response function can be effectively studied by performing analysis of variance (ANOVA). The model summary statistics for mean diameter are given in table4. It is found that, quadratic model best suggested for the present investigation where $\mathrm{R}^{2}$ value is maximum. ANOVA for response surface model for mean diameter is presented in table-5. 
ANOVA is generally used to summarize the test for significance on individual model co-efficient. The value of "prob $>F$ " in the present case is less than 0.0001 . The value of "prob $>F$ " for the model is less than 0.0500 , which indicates that, model terms are significant. It reveals that, model terms have significant effect on the response parameter. The F-value of model in the present experimentation is 126.86. The model F-value of 126.86 indicates that the model is significant. It is found that, feed, radius, (feed $\times$ speed), (feed $\times$ radius), $($ Speed $\times$ Radius $),\left(\right.$ feed $\left.{ }^{2}\right),\left(\right.$ Spee $\left.d^{2}\right)$ and $\left(\right.$ Radius $\left.{ }^{2}\right)$ are the significant terms for mean diameter

Table -4

Model summary statistics

\begin{tabular}{|l|l|l|l|l|l|l|}
\hline $\begin{array}{c}\text { Sou- } \\
\text { rce }\end{array}$ & $\begin{array}{l}\text { Std. } \\
\text { Dev. }\end{array}$ & $\begin{array}{l}\text { R- } \\
\text { Squar } \\
\text { ed }\end{array}$ & $\begin{array}{l}\text { Adjus } \\
\text { ted } R- \\
\text { Squar } \\
\text { ed }\end{array}$ & $\begin{array}{l}\text { Predi } \\
\text { cted } \\
R-\end{array}$ \\
$\begin{array}{l}\text { Squar } \\
\text { ed }\end{array}$ & $\begin{array}{l}\text { PRES } \\
S\end{array}$ & $\begin{array}{l}\text { Rema } \\
\text { rks }\end{array}$ \\
\hline $\begin{array}{l}\text { Linea } \\
\text { r }\end{array}$ & 0.69 & 0.039 & - & - & 11.19 & \\
\hline 2FI & 0.74 & $\begin{array}{l}0.143 \\
4\end{array}$ & $\begin{array}{l}- \\
0.370\end{array}$ & $\begin{array}{l}- \\
2.359\end{array}$ & 21.35 & \\
\hline $\begin{array}{l}\text { Quad } \\
\text { ratic }\end{array}$ & $\mathbf{0 . 0 7 4}$ & $\begin{array}{l}\mathbf{0 . 9 9 3} \\
\mathbf{9}\end{array}$ & $\begin{array}{l}\mathbf{0 . 9 8 6} \\
\mathbf{1}\end{array}$ & $\begin{array}{l}\mathbf{0 . 9 0 2} \\
\mathbf{5}\end{array}$ & $\mathbf{0 . 6 2}$ & $\begin{array}{l}\text { Sugg } \\
\text { ested }\end{array}$ \\
\hline
\end{tabular}

\subsection{Regression statistics}

Regression statistics for the developed model are given in Table-6. The co-efficient of determination $\left(\mathrm{R}^{2}\right)$, is used to find out approximation of the developed regression model. If $\mathrm{R}^{2}$ value is equals to 1 , it provides exact match. When residual increases the value of $R^{2}$ decreases in the range from 1 to 0 . The residual can be decreased by increasing the number of input variables. A more precise regression model can be obtained by adjusting co-efficient of determination $\left(\mathrm{R}^{2}\right)$ value for the degrees of freedom. Adj. $\mathrm{R}^{2}$ is used for this purpose. Adj. $\mathrm{R}^{2}$ compares residuals per unit degree of freedom. Adequate precision used to compare the range of predicted values at the design points to the average prediction error. It is the measure of Signal-to-Noise (S/N) ratio. The ratio more than 4 indicates adequate model discrimination. In the present case, the ratio is 31.40 , which is much above 4 . Hence the developed regression model could navigate response space. The co-efficient of discrimination, $\mathrm{R}^{2}$ value required should be closer to 1 . In the present experimention, the $\mathrm{R}^{2}$ value for the developed model is 0.9939 close to 1 , which is desirable.

The adequacy of the model also confirmed by the examination of residuals. The normal probability plot and plot of residuals versus predicted response are used to examine the residuals. The condition for the model to be adequate is that, normal probability plot of the residual should give a straight line and plot of residuals versus predicted response should be structure less and should not have any obvious pattern. The normal probability plot for mean diameter is shown in fig. 3. From the plot it is clear that, residuals forms straight line and hence the errors are distributed evenly.

Table -5

ANOVA table for response surface model ( Mean diameter)

\begin{tabular}{|c|c|c|c|c|c|c|}
\hline Source & $\begin{array}{l}\text { Sum of } \\
\text { squares }\end{array}$ & $\begin{array}{l}D \\
O \\
F\end{array}$ & $\begin{array}{l}\text { Mean } \\
\text { Squ- } \\
\text { are }\end{array}$ & $\begin{array}{l}F- \\
\text { Value }\end{array}$ & Prob $>F$ & Remarks \\
\hline Model & 6.32 & 9 & 0.70 & $\begin{array}{c}126.8 \\
6 \\
\end{array}$ & $<0.0001$ & $\begin{array}{c}\text { Significan } \\
\mathrm{t}\end{array}$ \\
\hline A-Feed & 0.13 & 1 & 0.13 & 23.97 & 0.0018 & $\begin{array}{c}\text { Significan } \\
t\end{array}$ \\
\hline B-Speed & 0.00001 & 1 & 0.00001 & 0.002 & 0.9634 & \\
\hline C-Radius & 0.12 & 1 & 0.12 & 20.82 & 0.0026 & $\underset{t}{\text { Significan }}$ \\
\hline $\mathrm{AB}$ & 0.16 & 1 & 0.16 & 29.65 & 0.0010 & $\begin{array}{c}\text { Significan } \\
\mathrm{t}\end{array}$ \\
\hline $\mathrm{AC}$ & 0.40 & 1 & 0.40 & 71.74 & $\begin{array}{c}< \\
0.0001\end{array}$ & $\begin{array}{c}\text { Significan } \\
\mathrm{t}\end{array}$ \\
\hline $\mathrm{BC}$ & 0.10 & 1 & 0.10 & 18.51 & 0.0036 & $\begin{array}{c}\text { Significan } \\
\mathrm{t}\end{array}$ \\
\hline
\end{tabular}


Experimental investigations to predict mean diameter of AA6082 tube A DOE approach

\begin{tabular}{|c|c|c|c|c|c|c|}
\hline$A^{2}$ & 5.15 & 1 & 5.15 & $\begin{array}{c}931.4 \\
3\end{array}$ & $\stackrel{<}{0.0001}$ & $\underset{t}{\text { Significan }}$ \\
\hline$B^{2}$ & 0.15 & 1 & 0.15 & 26.40 & 0.0013 & $\begin{array}{c}\text { Significan } \\
t\end{array}$ \\
\hline $\mathrm{C}^{2}$ & 0.021 & 1 & 0.021 & 3.86 & $0 . .0901$ & \\
\hline Residual & 0.039 & 7 & 0.0055 & & & \\
\hline Cor Total & 6.36 & $\begin{array}{l}1 \\
6\end{array}$ & & & & \\
\hline
\end{tabular}

Table -6

Regression statistics

\begin{tabular}{|c|c|}
\hline Std. Dev. & 0.074 \\
\hline Mean & 44.13 \\
\hline C.V. \% & 0.17 \\
\hline PRESS & 0.62 \\
\hline R-Squared & 0.9939 \\
\hline Adj R-Squared & 0.9861 \\
\hline Pred R-Squared & 0.9025 \\
\hline Adeq. Precision & 31.40 \\
\hline
\end{tabular}

The plot of residuals versus predicted response for the mean diameter of flow formed tube is shown in fig. 4. The plot of residuals gives no obvious structure, which confirms that, the predicted model is adequate. The plot of predicted versus actual for mean diameter is shown in fig. 5. The plot of predicted versus actual gives straight line, which indicate consistency of the developed model.

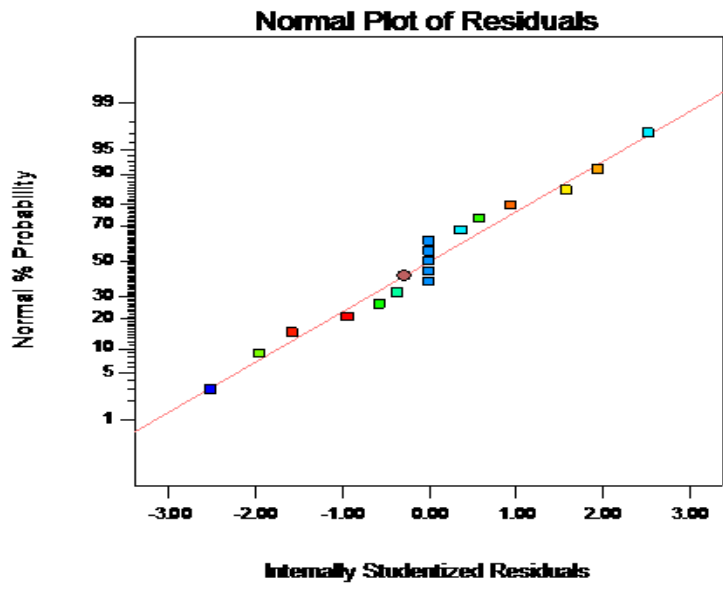

Fig. 3. Normal probability plot of residuals for mean diameter

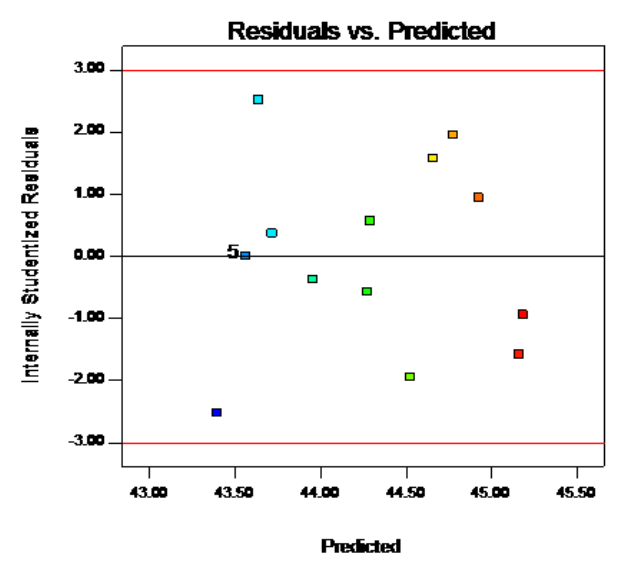

Fig. 4. Plot of residuals versus predicted mean diameter 


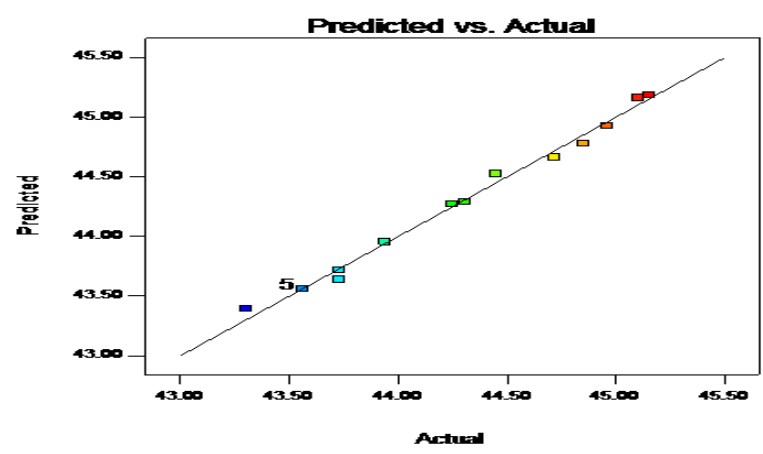

Fig 5. Plot of predicted values versus actual values for mean diameter

\subsection{Response surface graphs}

The three dimensional surface plots can be used to predict mean diameter values of flow formed tube for any suitable combination of input parameters. The three dimensional surface plots for the mean diameter are shown in fig. 6-8. Fig.6 shows the effect of roller feed and mandrel speed on the mean diameter of flow formed tube. The mean diameter first increases and then decreases with roller feed. Higher speeds of mandrel produce tubes with smaller mean diameter. The plastic deformation is insufficient at lower feed and becomes excess when it is at higher level. A feed of $75 \mathrm{~mm} / \mathrm{min}$ produces lower roundness error. The speed of the mandrel does not have much influence on the mean diameter.

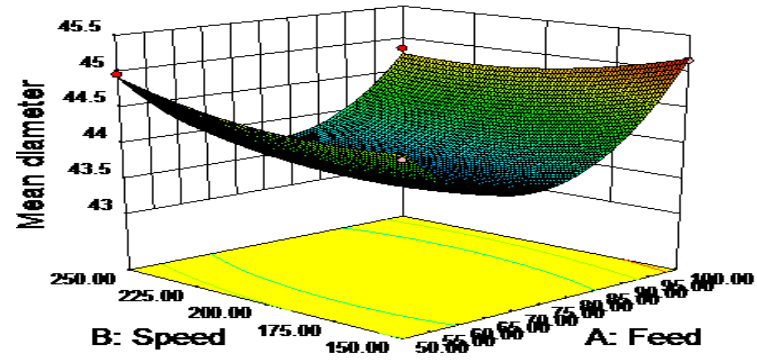

Fig. 6. 3D plot of feed and speed on mean diameter at radius $=8 \mathrm{~mm}$.

Fig.7 shows the three-dimensional surface plot of roller feed and roller radius on the mean diameter of flow formed tube. The mean diameter of flow formed tube increases with radius of roller. High forming forces resulted due to increase in radius responsible for larger mean diameter. A radius of $4 \mathrm{~mm}$ combined with a feed of $75 \mathrm{~mm} / \mathrm{min}$ forms the tubes with minimum mean diameter.

Fig. 8 shows three-dimensional plot of roller radius and mandrel speed at feed $=75 \mathrm{~mm} / \mathrm{min}$ on the mean diameter of flow formed tube. From the surface graph, is it clear that, a mandrel speed of in the range of 190$230 \mathrm{rpm}$ manufactures the flow formed tubes with minimum mean diameter.

A roller feed of $65-80 \mathrm{~mm} / \mathrm{min}$, roller radius of 4-6 $\mathrm{mm}$ and mandrel speed of $190-230 \mathrm{rpm}$ produces the flow formed tube with minimum mean diameter.

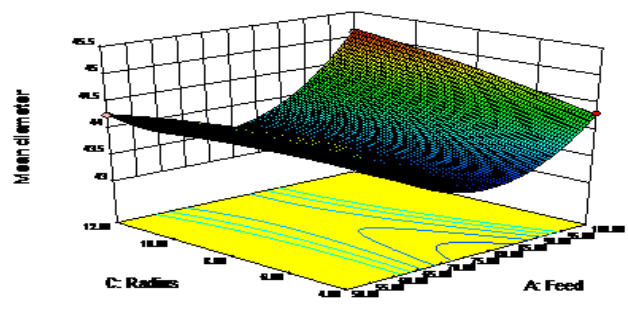

Fig. 7. 3D plot of feed and radius on mean diameter at speed $=200 \mathrm{rpm}$. 


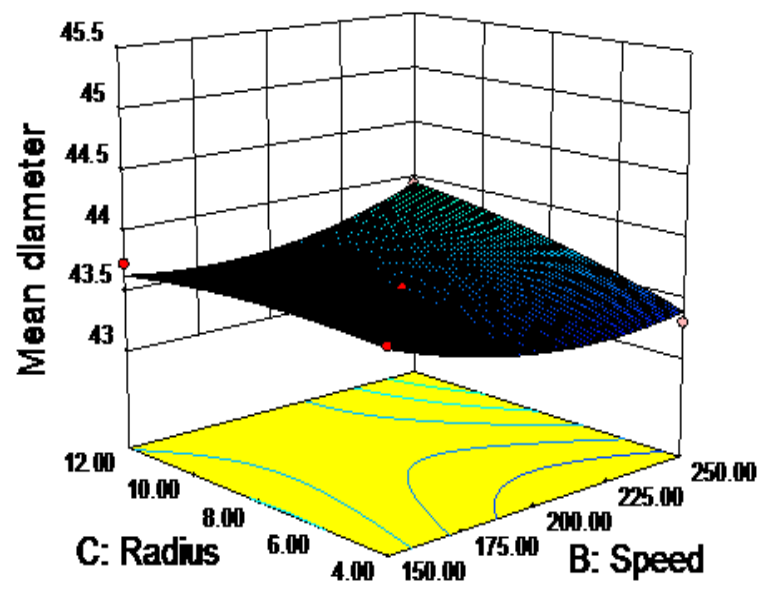

Fig. 8. 3D plot of speed and radius on mean diameter at feed $=75 \mathrm{~mm} / \mathrm{min}$.

Table -7

Sample predicted data from response surface model

\begin{tabular}{|c|c|c|c|c|c|c|}
\hline \multirow{2}{*}{$\begin{array}{c}\text { Sl. } \\
\text { No. }\end{array}$} & \multicolumn{3}{|c|}{ Parameters } & \multicolumn{2}{c|}{ Mean diameter, } & \\
\cline { 2 - 6 } & Feed & Speed & Radius & $\begin{array}{c}\text { Exper } \\
\text { iment } \\
\text { al }\end{array}$ & $\begin{array}{c}\text { RSM } \\
\text { Predic } \\
\text { ted }\end{array}$ & $\begin{array}{c}\text { Error } \\
\%\end{array}$ \\
\hline $\mathbf{1}$ & $\mathbf{6 0}$ & $\mathbf{2 2 0}$ & $\mathbf{1 2}$ & $\mathbf{4 3 . 8 5}$ & $\mathbf{4 3 . 8 8}$ & $\mathbf{0 . 0 7 5}$ \\
\hline $\mathbf{2}$ & $\mathbf{7 5}$ & $\mathbf{1 6 0}$ & $\mathbf{8}$ & $\mathbf{4 3 . 7 0}$ & $\mathbf{4 3 . 6 8}$ & $\mathbf{0 . 0 4 6}$ \\
\hline $\mathbf{3}$ & $\mathbf{8 0}$ & $\mathbf{2 0 0}$ & $\mathbf{4}$ & $\mathbf{4 3 . 3 9}$ & $\mathbf{4 3 . 3 8}$ & $\mathbf{0 . 0 3 3}$ \\
\hline
\end{tabular}

VII. CONFIRMATION TEST

A confirmation test is required to validate the developed model. Confirmation run was performed by setting the input parameters within the range of selected levels. The percentage of error was determined from the experimental value and corresponding predicted value. The experimental and predicted values are given in table-7. The maximum percentage of error is found to $0.075 \%$, which is within the allowable limits. Hence, the response equation developed for mean diameter of flow formed tube can be used to successfully predict the mean diameter values for any combination of input parameters within the range of defined levels.

\section{CONCLUSIONS}

In this research, response equation for mean diameter of flow formed tube has been developed by response surface methodology (RSM) for different input process parameters namely roller feed, mandrel speed and radius of roller. The predicted model can successfully navigate the response (mean diameter) within the range of selected levels. The confirmation test proves that, experiment values are in good agreement with predicted values.

\section{ACKNOWLEDGEMENTS}

The authors wish to express their thanks to Sri R.K. Gelli, Managing Director and Sri Koushik Gelli, Director M/s Spinmet Engineers Pvt. Ltd., Secunderabad, India, for providing all the facilities to carry out the experiments and to Mr. Theopelos and Technicians of Spinmet for their support and assistance in performing this work.

\section{REFERENCES}

[1] S. Kalpkcioglu, A study of shear-spinnability of metals, Transactions of ASME, Journal of Engineering. Industries, 83, 1961, 478-483. 


\section{Experimental investigations to predict mean diameter of AA6082 tube A DOE approach}

[2] T. Ram Mohan, and R. Mishra, Studies on the power spinning of tubes, International Journal of Production Research 10(4), 1972, 351-364.

[3] Rajanish Prakash, and R.P. Singhal, Shear spinning Technology for manufacture of long thin wall tubes of small bore, Journal of Material Processing Technology, 54(1-4), 1995, 186-192.

[4] Park Jae-Woo, Kim Young-Ho and Bae Won-Byong, Analysis of tube-spinning processes by the upper-bound stream function method, Journal of Material Processing Technology, 66, 1997, 195-203.

[5] K.S. Lee and L. Lu, A study on the flow forming of cylindrical tubes. Journal of Material Processing Technology, 113, 2001, 739-742.

[6] C.C. Wong, J. Lin and T.A. Dean, Effects of roller path and geometry on the flow forming of solid cylindrical components Journal of Material Processing Technology, 167, 2005, 344-353

[7] Makoto Murata, Takashi Kuboki and Tutom Murai, Compression spinning of circular magnesium tube using heated roller tool, Journal of Material Processing Technology, 162-163, 2005, 540-545.

[8] M. Joseph Davidson, K. Balasubramanian and GRN. Tagore, An experimental study on the quality of flow-formed AA6061 tubes, Journal of Material Processing Technology, 203, 2008, 321-325.

[9] N.A. Razani, A. Jalali Aghchai, and B. Mollaei Dariani, Experimental study on flow forming process of AISI 321 steel tube using the Taguchi method, Proceedings of. I Mech E, Part E: Journal of Process Mechanical Engineering, 225, 11, 2011, 2024-2031.

[10] M. Alauddin, MAEI. Baradie, MSJ. Hashmi, Prediction of tool life in end milling by response surface methodology, Journal of Material Processing Technology, 71 (3),1997, 456-465.

[11] V. Gunaraj, and N. Murugan, Application of response surface methodology for predicting weld bead quality in submerged arc welding of pipes, Journal of Material Processing Technology, 88, 1999, 266-275.

[12] Jae-Seob Kwak, Application of Taguchi and response surface methodologies for geometric error in surface grinding process, International Journal of Machine Tools and Manufacture, 45, 2005, 327-334.

[13] M. Joseph Davidson, K. Balasubramanian and GRN. Tagore, Surface roughness prediction of flow-formed AA6061 alloy by design of experiments, Journal of Material Processing Technology, 202, 2008, 41-46.

[14] M. Srinivasulu, C.S. Krishna Prasada Rao, and M .Komaraiah, Experimental investigations on the surface roughness of AA6082 flow formed tubes: A Taguchi approach, International Journal of Applied Engineering Research, 6 (4), $2011,523-532$. 